\title{
THE USE OF DRILL, VOCABULOUS (VOCABULARY VARIOUS) AND COMPUTER ASSISTED LANGUAGE LEARNING (CALL) IN LEARNING VOCABULARY
}

\author{
Nur Fauzia \\ Universitas Negeri Surabaya \\ nurfauzia@unesa.ac.id \\ Yuri Lolita \\ Universitas Negeri Surabaya \\ yurilolita@unesa.ac.id
}

\begin{abstract}
This study investigates the effectiveness of three vocabulary learning methods that are Contextual Clues, Dictionary Strategy, and Computer Assisted Language Learning (CALL) in learning vocabulary among ESL learners. First, it purposes at finding which of the vocabulary learning methods namely Vocabulous (Vocabulary Various), Drill and CALL that may result in the highest number of words learnt in the immediate and delayed recall tests. Second, it compares the results of the Pre-test and the Delayed Recall Post-test to determine the differences of learning vocabulary using the methods. A quasi-experiment tested the effectiveness of learning vocabulary using Dictionary Strategy, Contextual clues, and CALL involved 40students. Qualitative procedures included the collection of data from interviews which were conducted to triangulate the data obtain from the quantitative inquiries. Findings from the study using ANOVA revealed that there were significant differences when students were exposed to Vocabulous, Drill and CALL in the immediate recall tests but not in the Delayed Recall Post-test. Also, there were significant differences when $t$ test was used to compare the scores between the Pre-test and the Delayed Recall Post-test in using the three methods of vocabulary learning. Although many researchers have advocated the relative effectiveness of Vocabulous, Drill, and CALL in learning vocabulary, the study however, is still paramount since there is no study has ever empirically investigated the relative efficacy of these three methods in a single study.
\end{abstract}

Keywords: drill, Vocabulous (Vocabulary Various), Computer Assisted Language Learning (CALL), vocabulary learning methods

\section{INTRODUCTION}

Vocabulary is one of the components that should be mastered by people. People should master vocabulary in order to be able to communicate with others. Without mastering vocabulary, people are not able to know the meaning of the words or phrases and know how to use them in daily life. Thus, mastering 
vocabulary can facilitate people to enhance their skill and communicate successfully.

Nunan (2005: 121) argues that vocabulary is the collection of words that an individual knows. Coady and Huckin (1975: 5) state that "vocabulary is central to language and critical importance to the typical language learner". From the definition above, we can conclude that people had better to master vocabulary because vocabulary is the basic components in English. Furthermore, Allen (1997: 149) explains that vocabulary is one of the most important factors in language teaching. Liu (1998) expresses that inadequate vocabulary can be a major obstacle in the course of learning in the university. Folse (2004) argues that a sizable portion of vocabulary enables language learners to comprehend what they read or hear. In fact, vocabulary is one of the most important components in language learning and language curricula must reflect this notion (Folse, 2004).

The area of vocabulary learning and teaching has long been over looked by most linguists and language teachers (Vijayaletchumy Subramaniam, 2008). However, they contend that it is in these recent years that vocabulary learning and teaching has become "refreshed", and consequently has led linguists and language teachers to be involved in facilitating the vocabulary acquisition among language learners of English. Since then, linguists and language teachers have been keen on searching the most effective approaches and strategies for helping students develop vocabulary acquisition ( $\mathrm{Iu}, 2003$ ). Yet, vocabulary learning and teaching remains a debatable issue as people have differing opinions on how learners acquire vocabulary effectively and efficiently, or how it can best be taught (Cheung, 2007). Nevertheless, the vocabulary learning methods namely Drill, Vocabulous, and CALL can be taught to students in higher education.

\section{THE USE OF DRILL, VOCABULOUS AND CALL}

\section{The Use of Drill among Language Learner}

Based on that problem, teacher should give the right technique in teaching English. There are some techniques that can be applied in teaching speaking. One of them is chain drill, which is a part in the Audio Lingual Technique. This Technique emphasizes on drilling and practicing the pattern in teaching language. The students are asked to repeat what the teacher said like accuracy, dialog, and text. "Drills itself is a system of communication in written or spoken words, which is used by the people of a particular country or area" (Longman Dictionary of contemporary English, Advanced Learner's Dictionary, 2009).

Drilling is a technique that has been used in the second language classroom for many years. It was a key feature of audio-lingual technique which emphasis on repeating structural pattern through oral drill. Matthews, Spratt, and Dangerfield (1991: 210) said that "A drill is a type of highly controlled oral practice in which the students respond to given cue. The response varies according to the type of drill. Drills are used usually at the controlled practice stage of language learning so that students have the opportunity to accurately try out what they have learned.

The recently study from Megawati Dwi (2014) focuses on problem in teaching reading for students. She used drills technique to help the students in their reading activity. It shows that there are many problems in teaching reading, 
for example the students are lack of getting the main idea of the text. In the result of the study the researcher did not mention about the advantages of drilling in teaching reading. Furthermore, the design of the research is experimental quantitative research. The observer desires to present whether the use of drilling techniques gives any effect to students' reading descriptive text.

Here are series of drills which is designed to give beginning EFL students some practice with the structure.

1. Backward build-up drill (expansion drill). These series of drill is to break down the troublesome sentence into smaller parts. The lecture starts with the end of the sentence and has the class repeating just the last two words.

2. A Repetition Drill. The tasks are to listen carefully and attempt to mimic the lecture's models as accurately as possible.

3. Chain Drill. To give the student on opportunity to say the lines individually and let the students use the expression in communication with someone else, even though the communication is very limited.

4. Single-slot substitution Drill. The series of drill requires more than simple repetition in which the students will repeat a sentence from the dialog and replace a word or phrase the lecture give them. This word or phrase is called the cue which can be a picture.

5. Multi-Slot Substitution Drill. The series of drill list essentially the same type of drill as the single-slot substitution drill. However students must recognize what part of speech the cue word is and where it fits into the sentence for the cues have to be changed are the subject pronouns

6. Transformation Drill. The type of drill asks students to change one type of sentence into negative or active sentence into a passive.

7. Question and answer Drill.

8. The series of drill sometimes provide the students with situation that require a negative answer and sometimes with situations that a positive one. LarsenFreeman, Diane. (2000).

Cheung (2007) in an experimental study attempted to draw upon the achievement made by low achieving secondary students in guessing meaning from context. The study involved 80 students who were divided into two groups representing two modes of learning: the context and keyword methods. Results from her study found that the mean scores for the keyword method were much higher in both immediate and delayed recall tests. Students in the context method asserted that it was difficult for them to use the method since they were required to learn too many words at one time. As a consequence, it was perceived to be too challenging at some points.

\section{The Use of Vocabulous (Vocabulary Various) among Language Learners}

According to Nation (2001), word knowledge or vocabulary learning have been divided into two kinds, they are receptive vocabulary and productive vocabulary. Receptive vocabulary is a words that appeared or produce from reading and listening activities so that the reader or the listener can receive, accept, and get the words whether the words that they have read or heard before and even the new words for them. Then, Productive vocabulary is a words that they 
produce and make in written and oral form activities after they get receptive vocabulary before.

According to Pikulski and Templeton (2004), they state that the major way in which we "use" vocabulary is when we speak and write; the term expressive vocabulary is used to refer to both since these are the vocabularies we use to express ourselves. We "understand" vocabulary when we listen to speech and when we read; the term receptive vocabulary is used to refer to listening and reading vocabularies. Finally, to round out the terminology, meaning or oral vocabulary refers to the combination of listening and speaking vocabularies, and literate vocabulary refers to the combination of our reading and writing vocabularies. So, there are four kinds of vocabularies which is one skill related to other skills. To make clearly, there is an image which represent the points from Pikulski and Templeton stated.

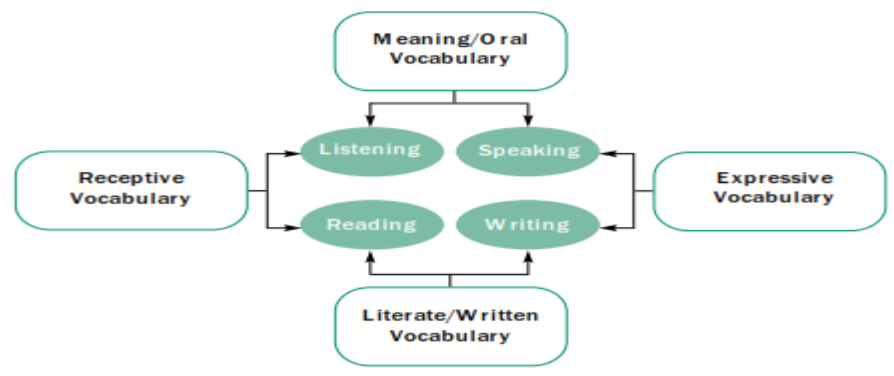

Figure 2.1: Relationship of the Eight Different Terms

\section{The Use of CALL among Language Learners}

Accuracy, real time immediacy and reliability (Liou, 1991) have made the learning of vocabulary using CALL more interactive (Relan, 1992). Such learning is important due to several reasons. These are the ability to increase learner autonomy, draw attention, arouse motivation, enhance learning, improve retention, provide immediate feedback, and supplement teachers' resources. These attributes are further elaborated in the subsequent discussions.

\section{Increase Learner Autonomy}

CALL increases autonomy among language learners. The one-on-one environment can activate students' learning because it provides them with rich and contextual environment. Fox (1984) showed that unscrambling or rebuilding text activity in CALL could provide a considerable control of students learning. Cloze exercises in the CALL program enabled undergraduates in the United Arab Emirate to manipulate relevant information which they found could be fed into a particular sentence.

\section{Draw Attention}

Teachers can draw students' attention by integrating pictures into multimedia forms. A study conducted by Yunan (2003) revealed that information aided with pictures and rich learning environment in multimedia instruction could arouse the learners' attention. Such was the result after 30 English and Literature students' achievements were accessed employing immediate recall tests. In the 
experimental study, two modes of CALL learning were used as the treatments to investigate the effectiveness of vocabulary acquisition (1) printed definitions with pronunciations, and (2) printed definitions with pictures and pronunciations. Both groups of learners were required to read selected passages and consulted the multimedia glossing or marked words in blue to hear their pronunciations as well as to read the English definitions. She concluded that the latter group stood to benefit the learning condition since pictures allowed for greater cognitive mapping and navigating in learning.

\section{Arouse Motivation}

The ease of using a CALL vocabulary program contributes to students' motivation. Nakata's (2008) study showed that the use of Low-First Method had positive effects on students' motivation, due to the tools were conducive to learning vocabulary. Such was the result when the use of computers was compared to List and Card. A total of 226 secondary school students participated in his study. He concluded a few important points after data was collected from the questionnaire, pre-test, immediate and delayed post-tests. First, they should be given time for rehearsal as the program was still new. Second, the teacher must help students understand how the program was designed to help improve their vocabulary.

\section{Enhance Learning}

The teacher's tailor-made vocabulary learning software program could enhance the learning of vocabulary among learners. This finding was evident in a study conducted by Kuen (2000) employing 20 foundation diploma students. In the study, software program namely Hot Potatoes enabled the teacher-researcher to create browser-based activities (Robb, 2004) which enhanced the learning of business vocabulary among the students. The interactive exercise allowed a deeper level of processing of the new words. They were made to pay more effort to repeat analyzing the choices given by recalling from their memory the meaning of the newly acquired words.

\section{Improve Retention}

Marked and unmarked vocabulary in a CALL program may improve students' ability in memorizing a word, and thus, promote vocabulary growth among learners. A study by de Ridder (2002) revealed that hyperlinks attracted students' attention to the words they were learning. Hyperlinks had a positive effect on vocabulary acquisition because words that were marked or highlighted received more attention than those which did not. Sixty second-year university students took part in the study. Marked (specific reading task) and unmarked (general reading task) vocabulary texts were used to gauge the usefulness of hyperlinks using a Latin-square design. Results of the immediate test showed that the there was no difference in the vocabulary loss between marked and unmarked conditions. This means that not using highlights, thus making the glossed words less graphically salient, did not particularly influence the incidental learning of vocabulary in a negative way. However, the results were contrary in the delayed test. Students in the marked condition were reported to click the highlights more 
excessively. As a result, they retained the words learnt longer than those in the unmarked condition.

\section{Provide Immediate Feedback}

In Hill's (1998) study, L1 meaning in Chinese characters was used to help the students learn the unknown words better. This feature enabled them to understand the meaning of the words before proceeding to answer the vocabulary items in a program called "Words in Your Ear". Consequently, when their answers were wrong, the program provided feedback in the form of definitions and contextualized examples of the inappropriate responses. However, feedback was not provided in the first attempt of answering a vocabulary item. Instead, it was only offered after three incorrect responses. The use of the program with such features was rated favorably by majority of 200 Chinese tertiary students in the study.

\section{Supplement Teachers' Resources}

Supplementary resource could benefit students in their vocabulary learning. Tsai and Jenks (2007) report that VocaWord, a vocabulary game could allow learners to practice the words they have learned while enjoying themselves at the same time. In fact, it was a good strategic game that provided the opportunity to challenge other players and also to learn new words from each other. He concluded that VocaWord was a promising game which could grab the interest of learners, and helped them acquire more words in a shorter time.

\section{Limitations of the previous studies}

The research reviewed in the earlier discussions have given the researchers some basic ideas about the use of Drill, Vocabulous and CALL in learning vocabulary among L2.Yet, the main limitations of the previous studies can generally be categorized in terms of their sample size, instruments, and tools used. First, in terms of sample size, most studies employed secondary school students (Cheung, 2007; Ngan-ha, 2007 \& Chung, 2008; Nakata, 2008). Second, concerning instruments, studies like Ngan-ha (2007) and Chung (2008) only included a single pre-test and post-test while Yunan (2003) only conducted several immediate tests to measure students' vocabulary achievements. Third, in learning vocabulary using CALL, all of the previous researchers used their respective CALL vocabulary programs. Based on these observations, the study attempts to integrate the uses of Dictionary Strategy, Contextual Clues, and CALL employing tertiary students as the samples. Also, the current study conducts several vocabulary achievement tests; pre-test, delayed recall tests and immediate recall tests, unlike previous researchers. Since previous studies used researcher-made CALL programs, the present study, however, attempts to use the pre-package language learning software namely TMM. Based on these arguments, the study aims at investigating the relative effectiveness of the three types of vocabulary learning methods in a single study. The following hypotheses are formed in respect to the objective of the study: 
H01 There is no significant difference in the achievement of the number of words learnt in theImmediate Recall Test 1 after receiving Vocabulous, Drill and CALL in learning vocabulary among students.

$\mathrm{H}_{02}$ There is no significant difference in the achievement of the number of words learnt in theImmediate Recall Test 2 after receiving Vocabulous, Drill and CALL in learning vocabulary among students.

$\mathrm{H}_{03}$ There is no significant difference in the number of words learnt between the Pre-test and the Delayed Recall Post-test using Drill among students.

Ho4 There is no significant difference in the achievement of the number of words learnt between the Pre-test and the Delayed Recall Post-test using Vocabulous among students.

H05 There is no significant difference in the achievement of the number of words learnt between the Pre-test and the Delayed Recall Post-test using CALL among students.

Ho6 There is no significant difference in the achievement of the number of words learnt in theDelayed Recall Post-test using Drill, Vocabulous, and CALL among students.

\section{METHOD}

The study uses quasi-experimental design, specifically the non-equivalent control group design as its method. The purpose of using the non-equivalent control group design is to investigate a situation in which random selection and assignment are not possible. A Pre-test was conducted to ensure the degree of equivalency among the comparison groups on the dependent variable before the experiment began (Key, 1997). Table 3.1 showed the design of the study. The study is conducted in six weeks. A Pre-test is conducted in the first week. The second and third weeks are allocated for lessons and tests. For these weeks, every first class meeting is allocated to learning sessions while immediate recall tests are administered in every second class meeting. A two-week gap of no vocabulary lessons and tests is scheduled in week four and five. In the sixth week, a Delayed Recall Post-test is administered to students. Besides that, interviews are conducted in week seven.

Table 3.1: The Non Equivalent Control Group Design Pre-test Post-test Design

\begin{tabular}{|c|c|c|c|c|c|c|c|c|}
\hline $\begin{array}{c}\text { Meeting } \\
1\end{array}$ & & $\begin{array}{c}\text { Meeting } \\
2\end{array}$ & & $\begin{array}{c}\text { Meeting } \\
3\end{array}$ & & $\begin{array}{c}\text { Meeting } \\
4\end{array}$ & $\begin{array}{c}\text { Meeting } \\
5\end{array}$ & $\begin{array}{c}\text { Meeting } \\
6\end{array}$ \\
\hline & & & & & & Break & & \\
\hline $\mathrm{Y} 1$ & $\mathrm{Xa}$ & $\mathrm{Y} 2$ & $\mathrm{Xa}$ & $\mathrm{Y} 3$ & $\mathrm{Xa}$ & - & & $\mathrm{Y} 4$ \\
\hline $\mathrm{Y} 1$ & $\mathrm{Xb}$ & $\mathrm{Y} 2$ & $\mathrm{Xb}$ & $\mathrm{Y} 3$ & $\mathrm{Xb}$ & - & & $\mathrm{Y} 4$ \\
\hline $\mathrm{Y} 1$ & $\mathrm{Xc}$ & $\mathrm{Y} 2$ & $\mathrm{Xc}$ & $\mathrm{Y} 3$ & $\mathrm{Xc}$ & - & & $\mathrm{Y} 4$ \\
\hline
\end{tabular}

\section{Y1: Pre-test}

Xa: First and second lessons using Drill

$\mathrm{Xb}$ : First and second lessons using Vocabulous

Xc: First and second lessons using CALL

Y2: Immediate Recall Test 1

Y3: Immediate Recall Test 2

Y4: Delayed Recall Post-test

- : Break of no lesson and test 
Table 3.2: Internal Consistency of Instruments

\begin{tabular}{|l|l|}
\hline Instruments & KR-20 Reliability Coefficient \\
\hline Pre-test & 0.77 \\
\hline Immediate Recall Test1 & 0.93 \\
\hline Immediate Recall Test2 & 0.98 \\
\hline Delayed Recall Post-test & 0.77 \\
\hline
\end{tabular}

\section{Subject}

The research subject is the students who are in secondary school especially for eight graders of junior high school students. The researcher conduct this research on the class VIII-A, there are 40 students in that class. Besides, the researcher also asks 8 students as the interviewer, there are 5 females and 5 males students. The researcher selects the classes that are represented by as homogeneous groups as possible. As the study uses preexisting intact group, all students in those particular classes are included as the subjects (Sytsma, 2009). The reason of choosing students in secondary school is because they are in intermediate position of learning English.

\section{Instruments}

Four vocabulary achievement tests are employed in the study. These are the Pre-test, Immediate Recall Test 1, Immediate Recall Test 2 and Delayed Recall Post-test. Also, two formats that are fill in the blanks and multiple choices are used for the design of all the tests. The fill-in-the-blank items require students to choose suitable meanings for the words that are underlined from four choices of answers. On the other hand, the multiple choices require them to choose answers that can be obtained by selecting words contain in the boxes allocated at the top of the test's section. The Pre-test and Delayed Recall Post-test involve testing students a total of 40 target words while 21 target words are tested in each of the immediate test. The Delayed Recall Post-test is equivalent to the Pretest to prevent students from remembering the subject matter being tested from the latter (Fraenkel \& Wallen, 2003). Besides that, semi-structured interviews are employed to support the hypotheses that are formulated in the study. Two competent and two basic learners in each vocabulary learning group, making a total of 10 respondents are called for the interview.

\section{Vocabulary Selection}

In considering the inclusion of target vocabulary, Read (2000) argues that there is no standard approach to the selection of target vocabulary for testing, yet, they may be selected from class texts or activities (Schmitt \& Schmitt, 1995). Most importantly, ensuring various parts of speech should be a priority (Folse, 2006) that can be achieved by conducting need analysis (Oxford \& Scarcella, 1994).Moreover, the number of target words should depend on the goal of the class, and 20 words per week should be sufficient for vocabulary enrichment (Schmitt \&Schmitt, 1995). Since effective vocabulary teaching depends on the 
students, the nature of the words, instructional purpose and strategies of learning vocabulary (Flanigan \& Greenwood, 2007), the sufficiency for instructions therefore, cannot be measured with the classroom time spent (Twaddel, 1973). Rather, vocabulary learning is an ongoing process especially in teaching the low context vocabulary (Mehring, 2005). The following procedures were followed in selecting the target vocabulary.

a) Analysis of target vocabulary was done by examining the words contained in 48 slides of the Fill in-the-Blanks exercise in the Vocabulary Workshop.

b) Fifty-two target words were preselected.

c) Four highly proficient students were appointed to make sentences using the target words.

d) Sentences written by them were checked by three teachers as examiners. They were only able to make sentences of 10 target words.

e) Forty-two words that are characterized by nouns, verbs and adjectives were determined as the target words for the study.

f) The selected words were confirmed by the English lecturers and teachers to enrich students' vocabulary.

\section{Item Analysis}

Item analysis is conducted to explore the research subjects' responses to each of the test item as to judge its quality (Mehrens \& Lehman, 1973). Generally, there are two measures which are calculated for each of the objective test items: the facility value or item difficulty and the discrimination index. The formulas by Mehrens and Lehman (1973) are used to calculate the item difficulty and item discrimination. In selecting good items, any test item with the value of 0.20 to 0.80 for the level of difficulty are considered acceptable (Mehrens \& Lehman, 1973). The final breakdown of all the test items showed that their difficulty ranged from 0.20 to 0.79 . Regarding the items for power of discrimination, any test items with the value of 0.20 to 1.00 is considered acceptable and can be kept in the question bank (Mehrens \& Lehman, 1973). The final breakdown of the whole items in the tests showed that their discrimination ranged from 0.20 to 0.83 .

\section{FINDINGS AND DISCUSSION}

Exploratory Data Analysis (EDA) was conducted to reveal the possible errors i.e. outliers in the data. Detecting them enables the researcher to establish the normal distribution of the data, and hence, determine whether parametric or non-parametric tests should be used (Field, 2009). Besides that, a Pre-test was conducted to examine possible differences in the vocabulary knowledge of the three groups among the students. The analysis of variance (ANOVA) in the Pre-test (Table 4.1) showed a non-significant result $[\mathrm{F}(2,120=1.413$, $\mathrm{p}=.248)$.The discussions that proceed concern with reporting the hypotheses of the study. 
Table 4.1: ANOVA of Pre-test to Determine Homogeneity of Subjects

\begin{tabular}{|l|c|c|c|c|c|}
\hline & Sum of Squares & Df & Mean Square & F & Sig. \\
\hline Between Groups & 57.63 & 2 & 28.81 & 1.413 & .248 \\
\hline Within Groups & 2447.90 & 40 & 20.40 & & \\
\hline
\end{tabular}

H01: There is no significant difference in the achievement of the number of words learnt in the Immediate Recall Test 1 after receiving Vocabulous, Drill and CALL in learning vocabulary among students.

A one-way ANOVA was used to explore the differences in the number of words learnt as measured by the Immediate Recall Test 1. From the analysis (Table 4.2), there was a statistically significant difference at the $p<.05$ level in the Immediate Recall Test 1 for the groups: $[\mathrm{F}(2,40)=7.365, p=.001]$. The effect size calculated using eta squared $(\eta 2)$ was 0.11 . The actual difference in mean scores among the groups was medium (Cohen, 1988). This also means the null hypothesis was rejected.

Table 4.2: Results of ANOVA of Immediate Recall Test 1

\begin{tabular}{|l|c|c|c|c|c|}
\hline & Sum of Squares & df & Mean Square & F & Sig. \\
\hline Between Groups & 640.04 & 2 & 320.022 & 7.365 & .001 \\
\hline Within Groups & 5213.96 & 40 & 43.450 & & \\
\hline Total & 5854.01 & 42 & & & \\
\hline
\end{tabular}

Further, a post hoc test using the Gabriel test was employed to further analyze which group differed from the other groups since sample sizes were slightly different (Field, 2009). The result presented in Table 4.2 showed that the mean scores for the Vocabulous group $(\mathrm{M}=22.33, \mathrm{SD}=8.55)$ was significantly different from the Drill group $(\mathrm{M}=16.67, \mathrm{SD}=5.22)$. The CALL group $(\mathrm{M}=$ $18.99, \mathrm{SD}=5.84$ ) did not differ significantly from either the Vocabulous or Drill group.

Table 4.3: Gabriel Post Hoc Test of Immediate Recall Test 1

\begin{tabular}{l|l|l|l|}
\hline Group & $(\mathrm{J})$ Group & Mean Difference (I-J) & Sig. \\
\hline Vocabulous & Drill & $5.663^{*}$ & .001 \\
\hline
\end{tabular}

Findings from the interviews are presented to justify the highest scores obtained by the Vocabulous group. First, in the interview, competent learners claimed that the various definitions guided their understanding on the meanings of the target words. However, the usefulness of various definitions in the monolingual dictionary was inconsistent with Chan's (2005) finding. Students in Chan's (2005) study were not able to remember the words learnt. They were unable to figure out the appropriate meanings of a multi-sense of word or the correct usage of a target word. Second, the advantages of examples of sentences in the vocabulary various might influence the students in the Vocabulous group to obtain the highest scores in the Immediate Recall Test 1 . However, such finding was inconsistent with Iu's (2003) finding. The results of the students' immediate recall test scores show that there are no difference in the amount of words learnt when target words are added 
to examples of sentences regardless of using bilingual and monolingual vocabulous. Third, students in the Vocabulous Strategy group scored the highest due to the benefits they gained from the phonetic symbols. Two competent learners who were interviewed claimed that learning the pictures were interesting because they were able to know the pronunciations of the target words. However, such finding does not correlate with the previous studies. In summary, the preceding discussions only highlighted the views made by the competent learners and ignored the views of the basic learners. However, it is done so as to triangulate with the results in the Immediate Recall Test 1. Such was so as to justify the highest scores obtained by the Vocabulous group.

H02: There is no significant difference in the achievement of the number of words learnt in the Immediate Recall Test 2 after receiving Vocabulous, Drill and CALL in learning vocabulary among students.

A one-way ANOVA indicated that there was a significant effect at the $p<.05$ level on the scores in Immediate Test 2 , $[\mathrm{F}(2,120)=6.812, p<.002]$. The eta squared ( $\eta 2)$ of 0.10 showed a small effect size (Cohen, 1998). The observed significant level that was lower than the 0.05 level also meant that the null hypothesis was rejected.

Table 4.4: Results of ANOVA for Immediate Recall Test 2

\begin{tabular}{|l|l|l|l|l|l|}
\hline & Sum of Squares & df & Mean Square & F & Sig. \\
\hline Between Groups & 792.836 & 2 & 396.418 & 6.812 & .002 \\
\hline Within Groups & 6983.551 & 40 & 58.196 & & \\
\hline Total & 7776.388 & 42 & & & \\
\hline
\end{tabular}

Further, post hoc comparisons using the Gabriel test that had great power was used since sample sizes were slightly different (Field, 2009). Table 4.5 showed that the mean scores for Drill group $(\mathrm{M}=30.01, \mathrm{SD}=6.78)$ was significantly different from CALL group $(\mathrm{M}=23.98, \mathrm{SD}=7.28)$. The mean scores for Vocabulous group did not differ significantly from either Drill or CALL group.

Table 4.5: Gabriel Post Hoc Test of Immediate Recall Test 2

\begin{tabular}{|l|l|l|l|}
\hline Group & (J) Group & Mean Difference (I-J) & Sig. \\
\hline CC & CALL & $6.03558^{*}$ & .001 \\
\hline
\end{tabular}

*. The mean difference is significant at the 0.05 level

However, such result is inconsistent with the finding derived from Çiftçi and Üster's (2009) study. They argued that students were highly successful in the sections parallel to the way they were taught. In their study, the students in the beginner level who are taking A Level were divided into two different vocabulary learning conditions. One group was exposed to learning vocabulary in context indicating the use and function of the word, and the other group was exposed to learning vocabulary by providing only the vocabulary various definitions of words. Findings from their study reveal that there is no significant difference between the two methods of vocabulary learning. Nevertheless, there are a number of reasons as to the effective use of Drill based on the interview conducted on the competent 
learners. First, they claimed that they would look at the clues near the target words to help them identify their meanings. The finding on guessing the meaning of a target word by looking at the clues is consistent with Chung's (2008) study. Her subjects used words that are closest to those of the target words, and hence, provided them sufficient information to understand their meanings. Second, think-aloud techniques help students in justifying their guesses. The advantage of this technique is consistent with Hamada's (2009) findings. Five Japanese college level ESL learners used the think-aloud technique to infer the meaning of unknown words after underlining them in a passage. Third, students perceived that figuring out meaning from context was analogous to a guessing game. They used their 'feelings' to insert the target words in the sentences.

H03: There is no significant difference in the number of words learnt between the Pre-test and the Delayed Recall Post-test using Drill among students.

A paired-samples t-test in Table 4.5 revealed that there was a significant difference between the Delayed Recall Post-test $(M=17.57, S D=6.221)$ and Pre-test $(\mathrm{M}=14.38, \mathrm{SD}=5.141) ; t(36), p_{.} .010$. The eta squared $(\eta 2)$ of 0.17 produced a medium effect size (Cohen, 1998). Since the observed significant level was lower than the 0.05 level, the null hypothesis, therefore, was rejected.

Table 4.6: Result of the Paired-Sample $t$ Test for the Drill group

\begin{tabular}{|l|l|c|c|c|c|c|c|}
\hline Treatment & & $\mathrm{N}$ & Mean & StandardDeviation & $\mathrm{t}$ & $\mathrm{df}$ & $\mathrm{p}$ \\
\hline Contextual & Pre-test & 40 & 12.68 & 3.97 & -7.285 & 42 & .000 \\
\hline Clues & $\begin{array}{l}\text { Delayed Recall } \\
\text { Posttest }\end{array}$ & 40 & 18.33 & 5.22 & & & \\
\hline
\end{tabular}

H04: There is no significant difference in the achievement of the number of words learn between the Pre-test and the Delayed Recall Post-test using Vocabulous among students.

Table 4.6 showed that there was a significant difference between the Delayed Recall Post-test $(\mathrm{M}=17.57, \mathrm{SD}=6.221)$ and Pre-test $(\mathrm{M}=14.38, \mathrm{SD}=5.141) ; \mathrm{t}$ (36), $p_{-} .010$. The eta squared $(\eta 2)$ of 0.17 produced a medium effect size (Cohen, 1998). Since the observed significant level was lower than the 0.05 level, the null hypothesis, therefore, was rejected.

Table 4.7: Result of the Paired-Sample $t$ Test for the Vocabulous group

\begin{tabular}{|l|l|c|c|c|c|c|c|}
\hline \multicolumn{1}{|c|}{ Treatment } & $\mathrm{N}$ & Mean & $\begin{array}{c}\text { Standard } \\
\text { Deviation }\end{array}$ & $\mathrm{t}$ & $\mathrm{df}$ & $\mathrm{p}$ \\
\hline $\begin{array}{l}\text { Dictionary } \\
\text { Strategy }\end{array}$ & Pre-test & 40 & 14.38 & 5.14 & -2.704 & 36 & .010 \\
\cline { 2 - 8 } & $\begin{array}{l}\text { Delayed Recall } \\
\text { Post-test }\end{array}$ & 40 & 17.57 & 6.22 & & & \\
\hline
\end{tabular}

H05: There is no significant difference in the achievement of the number of words learnt between the Pre-test and the Delayed Recall Post-test using CALL among students. 
The $t$ test results in Table 4.7 indicated that the students in CALL group obtained significantly higher scores in the Delayed Recall Post-test $(\mathrm{M}=18.27, \mathrm{SD}=4.46)$ than to the Pre-test $(\mathrm{M}=13.46, \mathrm{SD}=4.46) ; t(42)=-5.707, p_{-} .000$. The calculated eta squared ( $\eta 2$ ) with 0.44 produced a large effect size (Cohen, 1998). The observed significant value below 0.05 level resulted in the rejection of the null hypothesis.

Table 4.8: Result of the Paired-Sample $t$ Test for CALL group

\begin{tabular}{|l|ll|c|c|c|c|c|c|}
\hline Treatment & & $\mathrm{N}$ & Mean & $\begin{array}{l}\text { StandardDevi } \\
\text { ation }\end{array}$ & $\mathrm{t}$ & $\mathrm{df}$ & $\mathrm{p}$ \\
\hline \multirow{2}{*}{ CALL } & Pre-test & 40 & 13.46 & 4.460 & -5.707 & 42 & .000 \\
\cline { 2 - 8 } & $\begin{array}{l}\text { Delayed Recall } \\
\text { Post-test }\end{array}$ & 40 & 18.27 & 4.461 & & & \\
\hline
\end{tabular}

The results from the Pre-test and Delayed Recall Post-test scores reveal that all students in each group generally had made progress in learning vocabulary after they were taught to use Drill, Vocabulous, and CALL. This might be due to the following factors. First, the students might have benefited from the class discussions as Stahl and Clark (1987) affirm that discussions appear to improve vocabulary learning. In the lessons, it was observed that the students benefitted from pair and group works that was formed among their friends who were sitting close to each other. To a certain extent, the tasks or activities in the lessons provided the platform for them to reflect their learning through discussions. Second, it is also likely that the teacher made students focus on the techniques of using the methods in detail that yielded the improvement in the scores of the Delayed Recall Post-test. Although the students were instructed to follow their teacher, this did not mean that they were to totally depend on her. Yet, the teacher having the role of a facilitator and resource person negotiates with the students whenever they ask for clarifications (O'Neill \&McMahon, 2005). Besides, it is rather inappropriate for the teacher to spoon feed them as they are studying at tertiary level. They have other options to create their own learning in that they assimilate the techniques and apply those they find suitable when doing exercises in the lessons.

Ho6: There is no significant difference in the achievement of the number of words learnt in the Delayed Recall Post-test using Drill, Vocabulous, and CALL among students.

A one-way ANOVA was used to explore the differences in the achievement of the highest amount of words learnt as measured by the Delayed Recall Post-test. Table 4.8 showed that there was no statistically significant difference at the $p$ $<.05$ level in the Delayed Recall Post-test for the groups $[F(2,120)=.249, p$ $=.780]$. The no significant result obtained from the analysis, therefore, meant that the null hypothesis was accepted.

Table 4.9: Results of ANOVA for Delayed Recall Post-test

\begin{tabular}{|l|l|l|l|l|l|}
\hline & \multicolumn{1}{|c|}{ Sum of Squares } & \multicolumn{1}{c|}{ df } & \multicolumn{1}{c|}{ Mean Square } & F & Sig. \\
\hline Between Groups & 13.984 & 2 & 6.992 & .249 & .780 \\
\hline Within Groups & 3371.320 & 40 & 28.094 & & \\
\hline Total & 3385.304 & 42 & & & \\
\hline
\end{tabular}


The hypothesis that there would be significant differences when the students are exposed to learning vocabulary using Drill, Vocabulous and CALL in the Delayed Recall Post-test is not supported in the present study. The students demonstrated they were not able to remember all the words they learnt when they were tested in the delayed recall. It is not astounding that the students could not remember the words after a two-week break as they were not able to review them in that period. In fact, they were warned not to do so, and if otherwise committed, it would affect the results of the study. They only benefitted the revisions in the two lesson periods whereby they were given a few activities to familiarize themselves with the target words. It is apparent from the previous discussion that the finding of no statistical differences among the three treatments, tentatively suggested that it might be the amount of practice and reinforcement intervals, not the particular methods that impeded the students from acquiring the vocabulary for long term. The finding is consistent with the result obtained by Liu (1998) when she could not find any significant difference in the delayed recall post-test using three vocabulary learning methods namely Subjective Approach to Vocabulary (SAV), context method and CAI. While the data of Liu's study indicated that SAV method had the highest mean of correct word, the results were not conclusive enough to be statistically significant. Hence, she concluded that all vocabulary learning methods could produce better learning of the words, and no one method has shown to be consistently superior for long term retention.

\section{CONCLUSION AND SUGGESTION}

\section{Conclusion}

The present study has demonstrated the advantages of Vocabulous and Drill in the achievement of the number of words learnt in the immediate recall. However, for the delayed recall, it showed that all the three methods were not significantly different in helping the students to store the vocabulary for long term retention. Such findings are significant because although many researchers have advocated the relative effectiveness of Vocabulous, Drill, and CALL in the achievement of the number of words learnt, no study has ever empirically investigated the relative efficacy of these three methods in a single study. However, more research will be needed to address some limitations of the present study.

First, it might be valuable to extend the duration of the study. Interested researchers may extend the duration of the study to a period of a semester or fourteen weeks according to the general academic calendar in most local public school. Second, the current investigation was limited by the number of target words used for learning and testing. Having only 42 target words seemed to be quite small to be accounted for the vocabulary sample. Hence, having more target words enables students to learn the strategies and techniques of using Vocabulous, Drill and CALL to be more promising. The last concern was that the format of the tests that used multiple choice type answers and fill-in-the-blanks. Freely guessing the answers still offered an one-in-four possibility of them getting it correct, and thus, scoring one point for the question. Similarly, students might just want to get over with the fill-in-the-blanks questions. Hence, future researchers may use 
cloze-test to replace the existing format. For multiple-choice questions, they can provide two choices of answers instead of four for prospective students to choose from. This means they need to provide selection of true or false answer only.

\section{Suggestion}

In teaching and learning process, the teacher must give an extra attention to each student's learning vocabulary. The teacher must know the basic skill which includes the students' need and interest in learning. Besides that, the role of the teacher in the teaching and learning process is very important because teacher take attendance as the monitor while the students do the activity in the classroom. In order to make the students get the idea of that subject, the teacher must drill them in directly. Furthermore, the ability of the teacher is the important things in applying drill, vocabulous and CALL as the technique especially in teaching vocabulary because not all of the teacher can drill and give the good instruction for the students. The teacher should monitor how they do and try to guide them in learning vocabulary.

\section{REFERENCES}

Chen, P. C. (2008). The Effects of Utilizing Different Types of Printed Dictionaries on Vocabulary Acquisition, Retention and Reading Comprehension (Unpublished Doctoral Thesis). La Sierra University, California.

Cheung, C., Y. (2007). The effectiveness of vocabulary learning strategies of Chinese low achievers (Unpublished Master Thesis). Hong Kong University, Hong Kong.

Çiftçi, H., H. \& Üster, S. Comparative analysis of teaching vocabulary in context and by definition, Procedia Social and Behavioral Sciences, 1, 1568-1572.

Cohen, J. Statistical Power for the Behavioural Sciences. Hillsdale, HJ: Erlbaum.

Constantinescu, A., I. (2007). Using Technology to Assist in Vocabulary Acquisition and Reading Comprehension. The Internet TESL Journal, XIII (2), 122-133.

de Ridder, I., (2002). Does the Highlighting of Hyperlinks Affect Incidental Vocabulary Learning, Text Comprehension, and the Reading Process? Language Learning \& Technology, 6 (1), 123-146.

Field, A. (2009). Discovering Statistics Using SPSS (3rded.). London: Sage Publications Ltd.

Flanigan, K. \& Greenwood, S. C. (2007), Effective Content Vocabulary Instruction in the Middle: Matching Students, Purposes, Words, and Strategies, Journal of Adolescent \& Adult Literacy,51 (3), 226-238.

Folse, K.S., (2006). The Effect of Type of Written Exercise on L2 Vocabulary Retention, TESOL Quarterly, 40 (2), 273-293.

Fox, J. (1984). Computer-assisted vocabulary Learning, ELT Journal, 38 (1), 27-33.

Fraenkel, J. \&Wallen, N., (2003), How to Design and Evaluate Research in Education (5th ed.).McGraw Hill: New Jersey. 
Hamada, M. (2009).Development of L2 word-meaning inference while reading. System, 37 (3), 447-460.

Hill, M. (1998). Words in Your Ear: English vocabulary learning program, 3-6, Retrieved from ERIC database. (ED462003).

Hunt, A. (2009). Dictionaries and Vocabulary Learning: The Roles of L1 and L2 Information, $\quad$ Retrieved 8 March 2011 from http://hdl.handle.net/10112/760

Key., J., P. (1997). Research Design in Occupational Education. Retrieved 10 February 2009 from http://www.okstate.edu/ag/agedcm4h/academic/aged5980a/5980/newpage 2.htm

Kuen, S., M. (2000). Is using computer-based activities more effective than paper-based method in learning business vocabulary for vocational students? (Unpublished Master Thesis).University of Hong Kong, Hong Kong.

Larsen-Freeman, Diane. (2000). Techniques and Principles in Language Teaching. New York: Oxford University Press.

Lawson, M., J. \& Hogben, D. (1996). The Vocabulary-Learning Strategies of Foreign-Language Students, Language Learning, 46 (1), 101-135.

Liou, H.C. (1991). Development of an English Grammar Checker: A Progress Report, CALICO Journal, 9(1), 57-70.

Liu, J. (1998). The Effects of Three Methods of Vocabulary Instruction on Second Language Learning At the College Level (Unpublished Doctoral Thesis). University of Missouri-Kansas City, Missouri.

Mehrens, W. A., \& Lehmann, I. J. (1973). Measurement and evaluation in education and psychology, New York : Holt, Rinehart and Winston.

Mehring, J., G. (2005). Developing Vocabulary in Second Language Acquisition: From Theories to the Classroom, Retrieved July 4, 2011 fromhttp://www.hpu.edu/CHSS/International_Studies/TESOL/Professiona 1Development/200680TWPfall06/03Mehring.pdf

Morris, L., \& Cobb, T. (2004). Vocabulary Profiles as Predictors of the Academic Performance of Teaching English as a Second Language Trainees, Systems, 32, 75-87.

Nakata, T. (2008). English Vocabulary Learning with Word Lists, Word Cards and Computers: Implications from Cognitive Psychology Research for Optimal Spaced Learning, ReCALL, 20(1), 3-20.

Nassaji, H. (2006). The Relationship between Depth of Vocabulary Knowledge and L2 Learners' Lexical Inferencing Strategy Use and Success, the Modern Language Journal, 90 (3), 387-401.

O’Neill, G \& McMahon, T. (2005). Student-Centred Learning: What Does It Mean For Students and Lecturers? Paper presented at Emerging Issues in the Practice of University Learning and Teaching, Dublin. October 2005.

R.L., \& Scarcella, R.C. (1994). Second language vocabulary learning among adults: State of the art in vocabulary instruction. System, 22(2), 231-243.

Read, J. (2000). Assessing Vocabulary. Cambridge: Cambridge University Press.

Relan, A. (1992). Motivational Strategies in Computers-Based Instruction: Theories \& Models of Motivation, Retrieved from ERIC database. (ED 348017). 
Robb, T. (2004). Moodle: A Virtual Learning Environment for the Rest of Us, 8 (2), Retrieved November 3, 2011 from http://www.tesl-ej.org/wordpress/issues/volume8/ej30/ej30m2/

Schmitt, N. \& Schmitt, D. (1995) Vocabulary Notebooks: Theoretical Underpinnings and Practical Suggestions, ELT Journal, 49 (2), 133-143.

Sytsma, S. (2009). The Basics of Experimental Design, Retrieved 2 November 2009 fromhttp://liutaiomottola.com/myth/expdesig.html.

Tsai, R. \& Jenks, M., S. (2007). Using Computer Multimedia in the Classroom in a 'Teacher Guided' Mode: Vocabulary Acquisition in a University EFL Setting in Taiwan. Retrieved November 2, 2009 from http://www.editlib.org/p/25960

Twaddell, F. (1973), Vocabulary Expansion in the TESOL Classroom, TESOL Quarterly, 7 (1), 61-78

Vijayaletchumy Subramaniam, Mohd. Sahandri Gani Hamzah, Noor Aina Dani, Normaliza Abd Rahim, Nik Rafidah Nik Affendi \& Abdul Rashid Daing Melebek (2008). Learning Vocabulary through Image Sketching among Primary School Children, International Journal of Diversity in Organisations, Communities and Nations, 9 (2), 35-42.

Yunan, L. (2003). Effect of Two Annotation Modes on Vocabulary Learning and Retention in a Chinese EFL Context, Retrieved November 2, 2009 fromwww.cfl.cqu.edu.cn/cfls/zyk/jxzd/keyanlunwen/10.doc. 